University of Nebraska - Lincoln

DigitalCommons@University of Nebraska - Lincoln

June 2000

\title{
Avoiding Piano-related Injury: A Proposed Theoretical Procedure for Biomechanical Analysis of Piano Technique
}

Brenda Wristen

University of Nebraska--Lincoln, bwristen2@unl.edu

Follow this and additional works at: https://digitalcommons.unl.edu/musicfacpub

Part of the Music Commons

Wristen, Brenda, "Avoiding Piano-related Injury: A Proposed Theoretical Procedure for Biomechanical Analysis of Piano Technique" (2000). Faculty Publications: School of Music. 6.

https://digitalcommons.unl.edu/musicfacpub/6

This Article is brought to you for free and open access by the Music, School of at DigitalCommons@University of Nebraska - Lincoln. It has been accepted for inclusion in Faculty Publications: School of Music by an authorized administrator of DigitalCommons@University of Nebraska - Lincoln. 


\title{
Avoiding Piano-related Injury:
}

\section{A Proposed Theoretical Procedure for Biomechanical Analysis of Piano Technique}

\author{
Brenda G. Wristen, Ph.D.
}

\author{
Notice \\ Tlis moterial may be protected \\ hy copyright law. \\ Tille 17 U.S. Code
}

\begin{abstract}
Several biomechanical studies have been done with regard to the fingertip, hand, wrist; and upper arm in pianists. However, these studies have generally focused either on one isolated part of the anatomy, or on one specific motion. It is notable that none of the studies conducted to date examines the execution of a technical skill at the piano, such as a scale or arpeggio, in terms of the cooperative work done by all involved parts of the anatomy. Drawing upon established quantitative data, this study took a qualitative approach in describing and analyzing the execution of selected piano technical tasks. The procedure developed for conducting a biomechanical analysis can be readily applied in both medical and pedagogical venues with the goal of preventing injury. Med Probl Perform Art 15:55-64, 2000.
\end{abstract}

Focusing on human anatomy as a critical factor in piano technique is a somewhat recent innovation. Only since the late-nineteenth and early-twentieth centuries have pedagogues begun to address the motions of piano playing from a scientific or objective perspective. Some of their beliefs have been validated by later scientific observation. However, many of these pedagogues based their recommendations on an incomplete or even incorrect knowledge of anatomy and human motions. Their terminology in discussions concerning anatomy is frequently imprecise and many of the recommendations of these pedagogues are contradicted by medical, biomechanical, and/or ergonomic observations. Therefore, some of the practices and techniques recommended by these pedagogues have the potential to contribute to injury development.

Undertaking systematic qualitative analysis of movement patterns performed at the piano can offer valuable information in developing or modifying piano technique. In developing technique, students and teachers have typically relied primarily on recommendations of skilled performers. However, advice offered by individual players is most often based on individual subjective experiences. Though such recommendations may prove helpful, in many instances they may actually be counterproductive to the development of biomechanically appropriate piano technique. Understanding of human biomechanics has vastly improved in the last hundred years.

Dr. Wristen is assistant professor of piano at Chadron State College, Chadron, Nebraska.

Address correspondence and reprint requests to: Brenda G. Wristen, Ph.D., Chadron State College-Music Department, 1000 Main Street, Chadron, NE69337.e-mail: <buristen@csc.edu>.
With input from the recently developed sciences of ergonomics and biomechanics, it is now possible to examine piano technique in order to determine how the human body may be used maximally and most efficiently. Since medical, biomechanical, and ergonomic studies have theorized that some physical motions, most notably extreme wrist motions, can contribute to the development of an injury, it is worthwhile to examine piano technique with the aim of minimizing these motions. Unfortunately, qualitative studies with regard to motions used in piano playing have generally focused on motions so small and isolated from the integrated work done by the entire upper half of the body as to be completely inapplicable to practical piano technique.

Wagner is perhaps the most familiar name associated with biomechanics and anthropometry of the hand. ${ }^{1,2}$ However, Wagner dealt mostly with hand anthropometry, attempting to correlate relative success as a pianist to the size of the hand span and joint mobility. Wagner did attempt to measure active joint mobility, and demonstrated that the range of mobility in healthy joints, notably the metacarpophalangeal (MCP) 1, was very wide. He also observed that pianists employ a position of pronation for inordinate periods of time. From these data, he attempted to develop an "ideal" hand profile for success in piano performance based on hand measurements. He suggested that this profile might be useful in improving the performance of "those who do not belong to the small group of people who are manually specially gifted," specifically by identifying certain players as at risk for occupational injury and in contributing to the ergonomic design of the piano. However, Wagner did not attempt to address the application of biomechanical forces to the playing apparatus or hypothesize motions that may potentially lead to injury. He noted that this task was an important one to be addressed in the future, but was beyond the scope of his present study.

This project represents an attempt to identify potentially harmful motion in piano technique at large, and to theorize about normative motion patterns for selected skills. Types of overuse injuries commonly suffered by pianists were reviewed to discover presumable patterns of etiologies. Relevant medical, biomechanical, and ergonomic studies were reviewed to determine which motions used in piano playing may have the potential to cause injury. Building further upon theories gen- 
erated by these studies and established principles of biomechanics, theoretical motion pattern norms for executing certain pianistic tasks-scales, arpeggios, trills, double-third scales, octave scales, broken chords, and broken octaves-were postulated. It is not yet possible to conclude that adhering to general biomechanical theories and/or generalizations regarding motion patterns will prevent injury at the piano. However, the biomechanical norms devised in this project avoid motions/motion patterns that have been implicated, at least theoretically, in causing certain types of injuries.

A procedure for using these norms in conducting a qualitative biomechanical analysis of an individual pianist was adapted from a procedure established by J. R. Higgins ${ }^{3}$ for the observance and description of an athletic performance. While Higgins's method is somewhat dated, it has long been widely accepted as a basis for visual biomechanical analysis and is readily adaptable to the task of playing the piano. Additional considerations for the use of this procedure are discussed below.

\section{LITERATURE REVIEW AND BACKGROUND INFORMATION}

It was determined that in documented instances of injuries sustained by pianists, there was generally a common contributing motion or motions associated with each specific condition. Based on the review of published medical, biomechanical, and ergonomic studies, several motions frequently found in the pianist's technique were postulated as having the potential to contribute to injury development. In addition to harmful motions in the technique, it was found that certain practice habits contributed to injury development.

Pianists suffer from a variety of injuries that may be directly ascribed to practicing and/or performing. These include muscular pain syndromes, tendinitis, tendon entrapments, nerve entrapments, focal dystonias, and a host of other injuries. ${ }^{4-8}$ An injury is not necessarily the result of inappropriate technique. Individual genetic predisposition toward injury plays a central role in injury development; some individuals simply seem to be injured more easily than others. ${ }^{79,10}$ However, some easily controllable factors are related to injury development. The single most important recommendation to prevent injury is to avoid a sudden increase in the amount or intensity of practice. ${ }^{5,711}$ Other suggested controllable factors include the need for warming up muscles to their optimal functional temperature and cooling them down after practice to prevent muscle soreness and cramping. ${ }^{12}$

A number of biomechanical and ergonomic studies have identified specific positions and motions as risk factors for the development of certain injuries; thus, these positions should be viewed as potentially hazardous and avoided, especially for prolonged use. In order to minimize risk of injury in the fingers, Harding et al. recommended that the pianist avoid applying pressure after the key has "bottomed out" on the key bed since this practice has been shown to cause unnecessary joint and tendor ${ }_{\iota}$ stresses and will not contribute to sound production. ${ }^{13}$ Static finger or hand positions will likely lead to undue tension and inefficient motion; therefore, a variety of posi- tions should be employed. ${ }^{4.14}$ It has been suggested that increased carpal tunnel pressure (CTP) plays a role in the development of carpal tunnel syndrome, and possibly in finger flexor tenosynovitis as well. ${ }^{15}$ Subtle and temporal variations in CTP are strongly related to wrist angle. Gelberman et al. ${ }^{16}$ observed among both normal groups and groups afflicted with carpal tunnel syndrome, that CTP increases by a factor of two to ten with passive wrist extension and flexion. Building on this finding, Rempel demonstrated that the relationship of CTP to wrist angle is parabolic, increasing with greater degrees of wrist extension or flexion; increased CTP has been shown with as little as $15^{\circ}$ extension at the wrist. He observed a similar parabolic relationship with regard to increased degrees of radioulnar deviation. ${ }^{15}$ In addition to mechanical compression, Szabo and Madison postulate that the median nerve may be subjected to hydrostatic compression from fluids in the carpal tunnel during extreme wrist flexion and hyperextension..$^{17}$ In addition to wrist flexion and hyperextension, radial and ulnar deviation, pinching with the fingers, and extreme pronation or supination have all been linked to the development of carpal tunnel syndrome. ${ }^{18}$ At least one study has demonstrated a positive correlation between greater acceleration of flexion/extension movements and risk of developing carpal tunnel syndrome. ${ }^{19}$ Several medical and biomechanical studies have shown a correlation between pianistic tasks that require maintaining a large hand span (octaves and chords) or skills that use a wide range of wrist motion (arpeggios and some trills) and injury, especially wrist injury. ${ }^{20,21}$ Forceful pronation has been associated with pronator syndrome, while extreme elbow flexion and extension has been linked to cubital tunnel syndrome. Repetitive motions of high force, at both the wrist and forearm, have been associated with nerve entrapments in both locations; this correlation is so strong that it has been found to substantially increase the risk of carpal tunnel syndrome more than any other factor. ${ }^{22-24}$ Epidemiologic statistics also suggest that injury is more likely when working with cold hands or in a cold environment. Acute tendinitis has resulted after sudden exposure to temperatures below $0^{\circ}$ Celsius and cooling of innervated fingers has been shown to greatly affect strength, dexterity, and sensitivity. When working in a cold environment, people with normal sensory function tend to exert more force than is required, further increasing injury risk..$^{18}$

In the area of ergonomics, Meinke identified four laws of motion that theoretically apply to pianists:

1. Use of momentum to assist work

2. Use of smooth, curvilinear rather than straight, jerky motions

3. Use of the best-suited sers of muscles to accomplish work

4. Avoidance of wrist positions that deviate from neutral. ${ }^{25}$

Meinke theorized that there is frequently adverse momentum applied in piano playing. Expenditure of unnecessary energy should be minimized, and use of the free force of gravity should be maximized. The wrist should be maintained in a neutral position as much as possible. The most useful vector of momentum for the keystroke and movements that precede it is the central axis of the forearm to the fingertips. Any devi- 
I. Pre-observation Phase: Provided by Charts 1-7, which describe theoretical models for motion, breaking patterns down into component phases.

11. Observation Phase: Describe what is actively occurring during a given performance.

A. Record observations systematically.

B. Be sure to notice

1. The objective of the performer.

2. Whether or not the performer met the objective.

3. Any extraneous movements.

4. Any direct environmental influences (spatial or temporal constraints).

5. Any indirect environmental influences (noise, attire, equipment, etc.).

III. Postobservation Phase: Evaluate the performance and offer feedback.

A. What is the most appropriate feedback to provide the performer? Consider appropriate timing and hierarchical organization of feedback. Also weigh the potential of a motion that varies from the norm to contribute to injury.

B. What single aspect of the performance was most noticeable?

1. Good and bad features of movements.

2. Spatial and temporal constraints.

3. Body position, joint and segmental action, etc.

C. Were movements coordinated and efficient?

1. Was the goal attained? (consider observer's vs performer's assessment).

2. Did the performer execute the movements the way he or she planned?

3. Were there extraneous movements?

4. Were movements smoothly executed?

D. What environmental factors affected the performance?

1. Discuss effectiveness of the performer's movements in matching environmental constraints.

2. Identify and address indirect environmental influences.

\begin{abstract}
*Adapted with permission from: Arend S, Higgins JR: A strategy for the classification, subjective analysis, and observation of human movement. J Hum Movement Stud 2:49-50, 1976.
\end{abstract}

ation of the wrist from neutral tends to dissipate that vector into other nonproductive directions. ${ }^{25}$

Another factor that should be considered is the inverse relationship between experience and possible proclivity toward injury. Hillberry and others have demonstrated that keystrike force is lower for more experienced pianists than for less experienced ones. ${ }^{26}$ As the player progresses on the learning curve, he or she may be less vulnerable to injury, as motion patterns become less erratic. This observation might be true not only in terms of years of piano-playing experience, but in terms of the player's learning curve for a particular piece of music regardless of playing level. In playing a piece that is less familiar, pianists will likely use motions that are more "jerky" and less efficient than in a piece that has been practiced more.

\section{PROPOSED PROCEDURE FOR OBSERVATION AND BIOMECHANICAL ANALYSIS}

Motion pattern norms were theorized for the performance of the selected pianistic tasks, taking into consideration environmental, biomechanical, and morphological constraints. These motion pattern norms were formatted into checklists (Charts 1-7) to be used in conducting qualitative biomechanical analysis of an individual player as described in Table 1. It is important to note that these checklists describe observable motion only-they cannot provide, in and of themselves, information about how production of a certain motion feels to the player. Visible motion is but an outward sign of a healthy piano technique, often being produced by much finer, more minute muscular reactions. Thus these checklists cannot be used prescriptively in the teaching of a skill. In fact, instructing a player to consciously produce these visible motions can actually produce inappropriate physical tension. Piano pedagogy must concern itself with discovering methods to transmit this deeper, internal mastery of physical motion.

Instead of directly measuring and quantifying data, qualitative studies seek instead to describe and analyze the quality of movement. Such qualitative analysis can be used very effectively in examining piano technique. In order to conduct a qualitative analysis, basic knowledge of involved human anatomy and mechanical principles is necessary, as is a thorough understanding of the motor skill or movement pattern to be analyzed. ${ }^{27}$ Unfortunately, pianists are not generally experts on biomechanics, and biomechanicists/medical practitioners are often not experts with regard to the subtleties of piano technique. These checklists were designed to be used as general guidelines for visually examining a player's technique, representing a practical "middle ground" between the worlds of music and medicine.

Individual performer characteristics affect performance of a movement. These characteristics include the performer's age, gender, anthropometry, and developmental and skill level. Other special considerations, such as learning style or 
Parameters: Begins on a white key and is played hands-together ascending and then descending for a distance of four octaves. Note that a scale beginning on a black key uses the same motions, but begins at a different point in the sequence.

Technical Goal: Smooth linear projection of single notes, with no rhythmic inconsistencies, tempo fluctuations, or accents.

\begin{tabular}{|c|c|}
\hline Motion Category & Motion Description \\
\hline
\end{tabular}

personality type, may also impact performance. Other factors, such as whether the performer has had recent stress, or is tired, may also need to be considered. When working with small children, basing observations on adult norms may be counterproductive; children are not scaled-down adults. ${ }^{27}$ In addition to morphological considerations, environmental factors such as condition of the instrument, lighting, acoustics, and temperature of the room should also be taken into account.

It is important to follow a protocol when conducting a qualitative analysis. The number of procedural factors that must be considered increases with the complexity and desired degree of mastery of the movement being considered. Since movement patterns involved in executing skilled movement at the piano often occur on multiple planes, it is necessary to observe movement in all the involved planes. In the case of piano performance, motions are made in the frontal, sagittal, and transverse planes. Most of these motions may be observed from the side of the player at the level of the keyboard, or from above looking down on the hands on the keyboard. These positions allow for the observation of motions in the sagittal and transverse planes, and to some extent, the 
Parameters: Begins on a white key and is executed hands-together for four octaves. Note that arpeggios beginning on black keys use the same motions, but begin at a different point in the sequence. Note that while there is a qualitative difference between scale and arpeggio, the visual motion is similar, though larger.

Technical Goal: Smooth projection of single tone, with no rhythmic inconsistencies, tempo fluctuations, or accents.

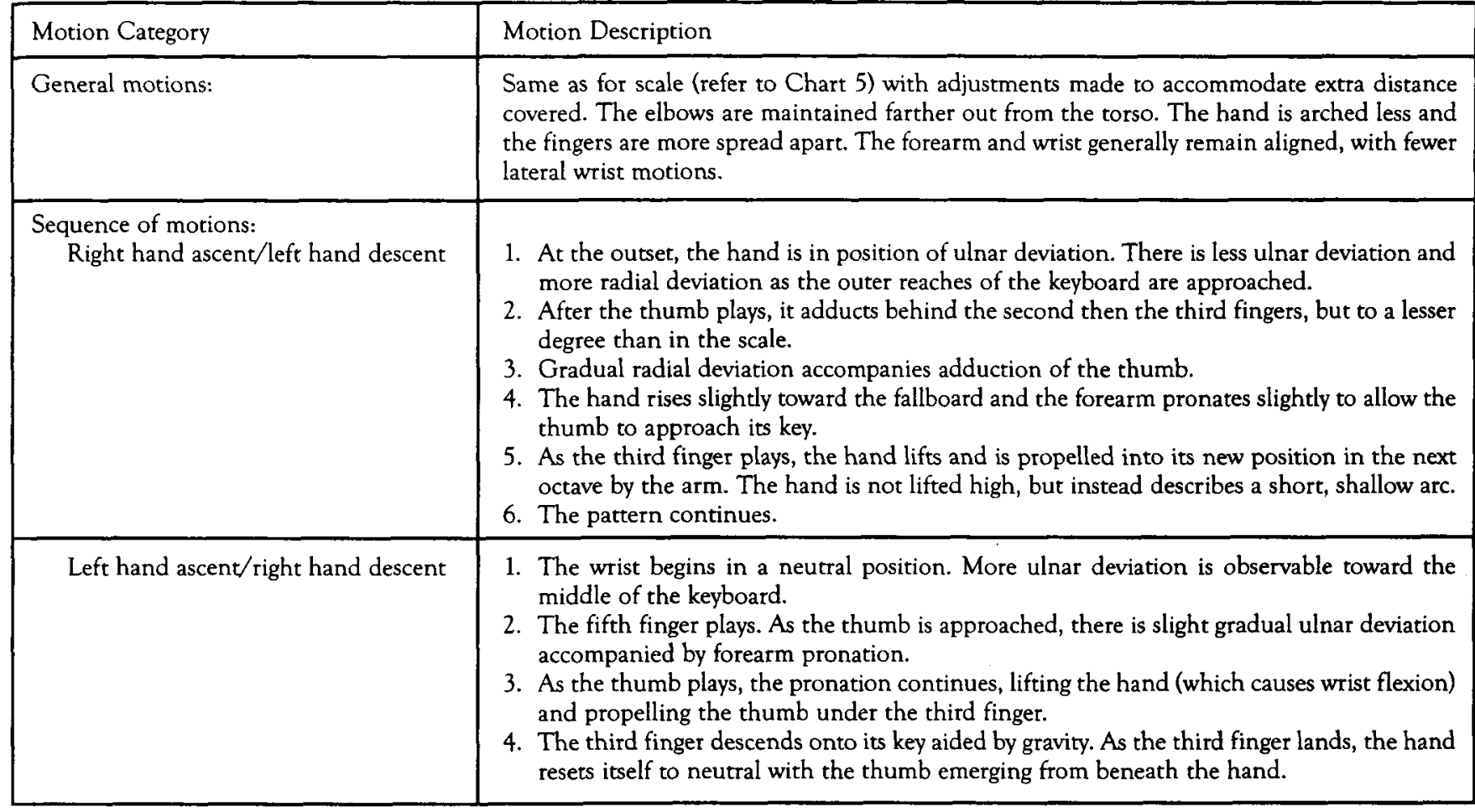

frontal plane. Another perspective that may be informative is from directly behind the player, where motions in the frontal plane may be observed if not obscured by the player's torso. This may necessitate the participation of more than one observer. Videotaping may be preferable since it minimizes variation in subjective response of multiple observers, and multiple cameras may be used to record motion in all planes simultaneously. Viewing distance must also be carefully considered and may need to be adjusted during the course of the analysis.

CHART 3. Checklist for Trills

Parameters: Rapid alternation of two keys on the keyboard, either white key to adjacent white key (may be separated by one black key), white key to adjacent black key, or black key to adjacent black key (may be separated by one white key).

Technical Goal: Even and rapid projection of both notes of the trill.

\begin{tabular}{|c|c|}
\hline Motion Category & Motion Description \\
\hline General motions: & $\begin{array}{l}\text { Weight suspended, but muscles of the upper back and shoulders are not strained. } \\
\text { Upper arm remains loose. } \\
\text { Forearm is at right angles to the keyboard. } \\
\text { Forearm forms a straight line with the midpoint between the two active fingers. } \\
\text { Wrist is slightly flexed so that the bones and joints of the active fingers are in a position for maximum stability } \\
\text { and leverage, freeing extensor tendons from unnecessary work. } \\
\text { Hand is free of tension. } \\
\text { Fingers are curved naturally. Small finger motions are the impetus for trills. Unused fingers do not contact keys. } \\
\text { Radial or ulnar deviation is required according to whether the trill is high (radial deviation) or low (ulnar devia- } \\
\text { tion) on the keyboard and whether black keys are involved. } \\
\text { In trilling from white key to white key, fingers play closer to key edge. } \\
\text { If black keys are involved, the hand is positioned more toward the fallboard, sometimes even on top of the black keys. } \\
\text { Player may make slight backward/forward adjustments with the arm or flexion/extension motions with the wrist } \\
\text { while trilling to maintain velocity. } \\
\text { Using too much forearm rotation will slow or stop trill. } \\
\text { Using too much arm weight will slow or stop trill. }\end{array}$ \\
\hline
\end{tabular}


Parameters: Simultaneous playing of thirds on one hand in a scalar (ascending and descending) progression.

Technical Goal: Smooth linear projection of double-thirds, with no rhythmic inconsistencies, tempo fluctuations, or accents.

\begin{tabular}{|c|c|}
\hline Motion Category & Motion Description \\
\hline $\begin{array}{l}\text { General motions: } \\
\text { Spine } \\
\text { Torso } \\
\text { Shoulders } \\
\text { Upper arm } \\
\text { Forearm } \\
\text { Wrist } \\
\text { Hand and fingers }\end{array}$ & $\begin{array}{l}\text { Spine is aligned with hips throughout. } \\
\text { Torso shifts from side to side along with center of gravity. Torso moves slightly ahead of the arms. } \\
\text { Shoulders are not raised. } \\
\text { Upper arm provides direction, abducting gradually as extremes of the keyboard are approached. Makes for- } \\
\text { ward/backward adjustments to allow for playing of black keys. } \\
\text { Guides motion of scale. } \\
\text { Wrist is maintained in a relatively straight line between the hand and the forearm. It makes slight rebound- } \\
\text { ing motions (small flexions and extensions) as each third is depressed. There is little to no lateral wrist } \\
\text { motion. } \\
\text { Palm is maintained in relatively open position throughout, but not rigidly. }\end{array}$ \\
\hline Sequence of motions & $\begin{array}{l}\text { 1. The right hand begins in a position of ulnar deviation. As the hand ascends, there is some radial devia- } \\
\text { tion, but less than in a single-note scale. The left hand would begin in a slight position of radial devia- } \\
\text { tion and turn toward the ulnar side as the middle of the keyboard is approached. } \\
\text { 2. After each third is depressed, the fingers rebound. They remain extended and ready for use, but the joints } \\
\text { are loose between key depressions. When playing double-third scales at a fast tempo, the fingers appear } \\
\text { to "flutter." } \\
\text { 3. To effect the hand shifts, the entire hand is lifted from the keyboard and propelled into the new position } \\
\text { by the forearm. }\end{array}$ \\
\hline
\end{tabular}

The observer may need to focus attention on a specific small part of the anatomy, or concentrate on larger areas. Attention to eye movements of the performer may also yield helpful information; a movement may be uncoordinated simply because the performer is not looking at the right part of the keyboard. Another factor to consider is the number of trials or executions of the movement, which should be observed before an analysis is undertaken. Highly-skilled performers may vary little from performance to performance, but less-skilled performers typically have high variability. The greater the inconsistency in the performer's technique, the larger the number of observations that should be made. ${ }^{27}$
Generally, the first step undertaken in a qualitative analysis is the formulation of a major question or questions of interest. This may involve determining which motions or movement patterns are to be observed. The second phase of analysis involves studying the questions of interest and hypothesizing about the interplay of mechanical principles, anatomic, environmental, and morphological constraints, and practical considerations of the movement. A systematic qualitative analysis will describe first what should happen, then what actually happens based on observation. Finally, by comparing expectations with outcomes, the analysis should evaluate the performance and describe feedback appropriate

CHART 5. Checklist for Octave Scales

Parameters: Execution of octaves by one hand in a scalar (ascending and descending) progression.

Technical Goal: Smooth, linear projection of octaves, with no thythmic inconsistencies, tempo fluctuations, or accents.

\begin{tabular}{|l|l|}
\hline Motion Category & Motion Description \\
\hline $\begin{array}{l}\text { General motions: } \\
\text { Spine }\end{array}$ & $\begin{array}{l}\text { Spine is aligned with hips throughout. } \\
\text { Torso shifts from left to right along with center of gravity. } \\
\text { Shoulders } \\
\text { Upper arm }\end{array}$ \\
$\begin{array}{l}\text { Shoulders are not raised. } \\
\text { Upper arm makes marked backward and forward adjustments to reach black keys. These motions should be } \\
\text { made smoothly, not in sudden jerks. Upper arm also guides direction of forearm. }\end{array}$ \\
$\begin{array}{l}\text { Fot actively involved; remains loose. } \\
\text { Provides impetus for keystroke. Sends small impulses through the wrist, which result in visible extensions } \\
\text { and return to neutral wrist position with each keystroke. Forearm, wrist, and hand are laterally aligned with } \\
\text { the wrist slightly higher than the forearm. } \\
\text { Hand and fingers } \\
\text { the hand in somewhat flattened, especially in a small hand, but is still present. Between keystrokes, the hand } \\
\text { remains open between the proximal interphalangeal joints of the playing fingers. However, the palm is not } \\
\text { rigidly maintained, but rebounds slightly after each key stroke. The unused inner fingers may contact the } \\
\text { keys without producing a sound as each octave is depressed. }\end{array}$ \\
\hline
\end{tabular}


Parameters: Execution of a pattern in one hand in which tones of a major triad are played one note at a time from the bottom to the top. After the root position is played (four notes: root, third, fifth, and next root), the pattern progresses to the next inversion by dropping down to the third (third, fifth, root, and next third).

Technical Goal: Even projection of tones, with no rhythmic inconsistencies, tempo fluctuations, or misplaced accents.

\begin{tabular}{|l|l|}
\hline Motion Category & Motion Description \\
\hline $\begin{array}{l}\text { General motions: } \\
\text { Spine } \\
\text { Torso } \\
\text { Shoulders } \\
\text { Upper arm }\end{array}$ & $\begin{array}{l}\text { Spine is aligned with hips throughout. } \\
\text { Torso shifts from left to right with the center of gravity. } \\
\text { Shoulders are not raised. } \\
\text { Upper arm makes backward and forward adjustments to allow for playing of black keys. Gives direction to } \\
\text { forearm. } \\
\begin{array}{l}\text { Elbow } \\
\text { Forearm } \\
\text { Wrist }\end{array}\end{array}$ \\
$\begin{array}{l}\text { Hand and fingers } \\
\text { Supinating and pronating motion is less pronounced than in broken octaves, but is still observable. } \\
\text { Lateral adjusting motions. } \\
\text { Fequence of motions: }\end{array}$ & $\begin{array}{l}\text { 1. After the thumb plays, there is a slight radial deviation when moving toward the fifth finger. This motion } \\
\text { is accompanied by a slight lifting of the hand, resulting in slight wrist flexion. }\end{array}$ \\
$\begin{array}{l}\text { 2. After the fifth finger plays, there is a resetting of the hand (slight ulnar deviation) in positioning the } \\
\text { thumb over the first note of each new inversion. The smaller the hand, the more lateral wrist motion is } \\
\text { observable. }\end{array}$ \\
$\begin{array}{l}\text { 3. The combination of lateral and vertical wrist motions results in a flattened circle described on the frontal } \\
\text { plane. }\end{array}$
\end{tabular}

for modifying subsequent performance. These steps describe the pre-observation, observation, and post-observation phases of a qualitative analysis. ${ }^{28}$

Charts 1-7 define the goal of the movement pattern, offer a breakdown of the component motions of a pattern, and describe the sequence in which these motions occur. These charts fulfill the pre-observation phase of the biomechanical analysis as described in Table 1 . With these basic visual norms in hand, piano teacher or medical practitioner will be able to observe an individual student performing one of the described skills, and offer critical feedback regarding the underlying causes of incorrect motion as outlined in the postobservation phase.

\section{RECOMMENDATIONS/CONCLUSIONS}

In general, the pianist should develop a technique characterized by integrated, coordinated motions, so that forces are distributed throughout the anatomy instead of being localized. Avoiding jerkiness in motion will allow tendons and muscles to stretch gradually and smoothly, avoiding impulse loading. Momentum should be used to aid in the playing

CHART 7. Checklist for Broken Octaves

Parameters: Alternate sounding of the two voices of an octave with the same hand in a scalar (ascending and descending) progression.

Technical Goal: Smooth linear projection of each side of the octave with no rhythmic inconsistencies, tempo fluctuations, or misplaced accents.

\begin{tabular}{|c|c|}
\hline Motion Category & Motion Description \\
\hline $\begin{array}{l}\text { General motions: } \\
\text { Spine } \\
\text { Torso } \\
\text { Shoulders } \\
\text { Upper arm } \\
\text { Elbow } \\
\text { Forearm } \\
\text { Wrist } \\
\text { Hand and fingers }\end{array}$ & $\begin{array}{l}\text { Spine is aligned with hips throughout. } \\
\text { Torso shifts from left to right with the center of gravity. } \\
\text { Not raised. } \\
\text { Upper arm makes backward and forward adjustments to allow for the playing of black keys. These motions } \\
\text { should be smooth, without any jerks. } \\
\text { Not actively involved; remains loose. } \\
\text { Pronation and supination. } \\
\text { Some vertical rebounding; little or no vertical motion. } \\
\text { Maintain loose shape; not rigid. }\end{array}$ \\
\hline Sequence of motions: & $\begin{array}{l}\text { Broken octaves are accomplished by alternately pronating then supinating the forearm with the wrist and fin- } \\
\text { gers remaining aligned with the forearm. There is little or no vertical motion made by the wrist. } \\
\text { Ulnar deviation of the hand is present in both the ascent and descent due to the continuous use of the } \\
\text { thumb. }\end{array}$ \\
\hline
\end{tabular}


TABLE 2. Recommendations for Preventing Piano-related Injury

General recommendations:

- Never practice through pain.

- Avoid suddenly increasing the time and/or intensity of practice.

- Divide practice into segments of no more than 30 minutes.

- Practice contrasting repertoire from one segment to the next.

- Spread segments throughout the day.

- Never suddenly increase practice time. If more time is needed, keep the length of the practice segments the same (or shorten it!) and gradually increase the number of segments.

- Use warm-up and cool-down exercises.

- Don't play when your hands are cold.

- Be aware of the inverse relationship between experience and proclivity toward injury.

- Participate in a general conditioning exercise program.

Avoid:

- Small, repetitive motions.

- Ulnar deviation, especially for prolonged periods. Be cautious when playing in outer extremes of the keyboard.

- Applying pressure to the key after it has "bottomed out" on the keybed.

- Continual extension of the hand/fingers.

- "Pounding" on the thumb.

- Using a static hand position.

- Dropping the wrist below anatomic neutral, especially dropping below the level of the keys.

- Abruptly arresting or changing the direction of any motion.

- Independently raising the fingers without assistance from larger muscles.

Promote:

- Smooth, well-coordinated motions.

- Follow-through motions that move upward.

- Returning the wrist to a neutral position as much as possible.

- Use of long arm motions instead of bouncing the wrist with every note.

- Breathing coordinated with musical phrases.

task. This includes the use of gravity in combination with kinetic motions of the entire upper limb. Where motion is ancillary or does not contribute to the task, it should be minimized or eliminated. As much as possible, extreme flexion or extension at the wrist should be avoided since these motions increase the work of the extensors and flexors of the fingers and wrist, and may eventually contribute to the development of carpal tunnel syndrome. Dropping the wrist below key level should also be avoided; wrist motions should be made gently and smoothly due to the demonstrated relation of sudden accelerations of wrist motion and injury.

The larger muscles of the upper arm and shoulder should be used to generate the kinetic energy need to move the upper limb over distances and provide strength, stability, and endurance. The forearm, hand, and fingers should be used to control this kinetic energy and provide speed for rapid movements at the level of the key. The need for this kinetic energy to pass unimpeded from the upper arm to the fingertips offers an additional reason to maintain neutral wrist position. The pianist should avoid abrupt, arresting, or jerky motions in changing the direction of movement. Abruptly changing direction requires much more energy than does applying a small amount of force obliquely to gradually change direction. Curvilinear motions should be used since movements through joints always describe arcs; curvilinear motion is especially important in covering distances at the keyboard, as when playing large leaps.

Because repetitive motion has been suggested as one of the factors that directly contribute to injuries, the pianist should attempt to use a variety of motions. Practice segments should be varied so that the pianist is not practicing the same physical motion (or by extension, the same musical passage) repeatedly. Finally, pianists should always be conscious of the relationship between experience and proclivity toward injury. When learning a new motion or skill, the player may be more vulnerable to injury, and extreme care should be taken so that injury does not result. A list of general recommendations for preventing overuse injury was developed from the above information and is provided in Table 2.

It would be futile to attempt to describe precisely the motions used by an individual player to accomplish a given skill; after all, every human body has some anatomic and physiologic idiosyncrasies and variations. However, apart from these individual differences, all human beings are constructed in basically the same way. Therefore, it is possible to derive general biomechanical observations that may apply to all pianists and can potentially aid in building appropriate technique, which should hypothetically lower the risk of injury by avoiding potentially hazardous motions. It is important to note that this type of biomechanical analysis can offer only visual information to the observer; it cannot inform the observer how motion feels to the player. Therefore, it is imperative that guidelines be used as just that; rigid application might actually contribute to tension or promote the use of inappropriate motions. However, it is useful to apply biomechanical principles to focus on specific parts of the playing apparatus when there is visual evidence of inefficient technique.

Though skilled performers are usually better equipped to analyze the quality of a performance, this is not always the case. The best pianists do not always make the best teachers. Instead of relying solely on personal experience, the piano teacher should consider relevant biomechanical and ergonomic considerations in teaching piano technique. There are several ways in which to pursue information about a given movement and the factors that affect it. One is to read pertinent articles from biomechanics research literature and from musical journals. However, many of the movement patterns used in piano playing are subtle and complex; not all of these patterns have been researched. It is important to distinguish between articles based on research and those based purely on conjecture or opinion. The skill checklists described here have integrated these factors and should aid teachers in making appropriate adjustments to an individual student's technique.

Nonvisual cues can also be useful in conducting qualitative analysis. The sound produced by a given movement can provide vital information about the relative success of the movement. For instance, is the sound harsh? Are there rhythmic inconsistencies? Perhaps the most important source of information is the performer himself or herself. Since only the performer knows how a movement feels, his or her feed- 
back is invaluable. However, it is important to note that not all performers are sufficiently kinesthetically attuned to their bodies to provide meaningful feedback. Moreover, often learning a new skill involves a certain degree of incoordination due to unfamiliarity, but this incoordination or discomfort should not be confused with actual physical pain.

There are several crucial considerations to be remembered in using the checklists of motion patterns provided here. The first is that the checklists may be used to analyze the movement pattern either as it occurs in an isolated technical exercise, or within repertoire as long as the passage has the same skill parameters as that described in the checklist. The second consideration is that hand size will affect motion at the piano, most notably, lateral adjusting motions effected by the wrist. In general, the smaller the hand, the greater the required degree of radial and ulnar deviation. A third factor to consider is that variations in tempo will affect observable motion. In general, the slower the tempo, the more pronounced and visible the motion. When executing the movement pattern at a faster tempo, the same motions are usually still present; however, the motions become smaller and sometimes even invisible. Fourth, sometimes attempting to think about and consciously integrate a motion can actually increase tension. In working toward a desired sound or movement, it is essential for the student to always remain conscious of physical comfort.

Finally, and most important, these checklists should be used only as a theoretical tool for developing injury-preventive technique. They should not be rigidly followed or used prescriptively; within the general movement pattern described, there is still room for individual execution variation and interpretation. In fact, teachers must be careful recommending a change in a student's technique based on these guidelines. Even if the student differs from the checklists, an adjustment in technique may not be called for if the student feels completely comfortable and no injury has been sustained; this is especially true for students with many years of playing experience. However, some motions, such as extreme flexion or extension at the wrist, should be corrected even in experienced players due to the great potential for injury. While some motions have clear potential for damage, other motions may or may not be changed based on comfort benefits for the student. The teacher must weigh the student's level of experience and consider the potential of any motion outside the norm to cause injury before recommending a change; the background information provided and the list of preventive recommendations (Table 2) will aid in making an informed judgment.

A great deal of further quantitative research is required if we are to develop conclusive strategies for injury prevention through a biomechanical approach to piano technique. It must be determined whether the motions used in an isolated task or exercise differ significantly from motions that occur in the larger context of a complete musical piece. Though range of motion has been normalized for most of the joints of the body, and studies have quantified the range of motion used by some of the joints used in piano playing, no study has examined the link between range of motion at the piano and the possible development of injury. Likewise, though biomechanical and ergonomic studies have theorized that certain physical motions contribute to injury development, it has yet to be determined how frequently and for what durations these motions must be used in order for injury to result. Though the nature of tendons has been extensively studied, at least in vivo, few studies have addressed muscle fiber tensile strength. Since many injuries suffered by pianists affect muscles, or muscle-tendon units, such studies might offer essential information about muscular tolerances at the cellular level. Studies need to be undertaken to determine whether there is a definite correlation between strength and occurrence of injury so that the role of strength conditioning, especially as it pertains to the fingers, may be defined. After these questions have been answered, quantified analysis of various motions employed at the piano would help answer whether those motions exceed biological tolerances. Most important, studies need to examine a multiplicity of motions used in piano technique and address how motions interact in playing tasks in order to develop a general dynamic model for piano technique.

\section{REFERENCES}

1. Wagner $\mathrm{CH}$ : Success and Failure in Musical Performance. The Biology of Music Making: Proceedings of the 1984 Denver Conference. St. Louis, MMB, 1988, pp. 154-179.

2. Wagner $\mathrm{CH}$ : The pianist's hand: Anthropometry and biomechanics. Ergonomics 31:97-131, 1988.

3. Higgins JR: Human Movement: An Integrated Approach. St. Louis, Mosby, 1977, pp. 36-52.

4. Markison RE: Hands on fire. Keyboard 20(4):93-110, 1994.

5. Lockwood AH: Medical problems of musicians. N Engl J Med 320: 221-27, 1989.

6. Fry $\mathrm{HJH}$ : Overuse syndrome of the upper limb in musicians. Med J Aust 144:182-185, 1986.

7. Lederman RJ, Calabrese L: Overuse syndromes in instrumentalists. Med Probl Perform Art 1:7-11, 1989.

8. Sataloff RT, Brandfonbrener AG, Lederman RJ (eds). Textbook of Performing Arts Medicine. New York, Raven Press, 1991.

9. Fry $\mathrm{HJH}$ : Overuse syndromes in instrumental musicians. Semin Neurol 9:136-145, 1989.

10. Fry HJH: How to treat overuse syndrome: Medicine for your practice. Music Educ 72:46-49, 1986.

11. Brandfonbrener AG: Medical problems of musicians. Am Music Teacher 37(55):11-13ff, 1988.

12. Kella JH: Musculoskeletal, neurological, and dermal ailments of musicians. Int Musician 87:7ff, 1988.

13. Harding $\mathrm{DC}, \mathrm{Brandt} \mathrm{KD}$, Hillberry $\mathrm{BM}$ : Minimization of finger joint forces and tendon tensions in pianists. Med Probl Perform Art 4: 103-108, 1989.

14. Harmful practices that cause injuries. Clavier 33(2):13-24, 1994.

15. Rempel D: Musculoskeletal loading and carpal tunnel pressure. In Repetitive Motion Disorders of the Upper Extremity. Rosemont, IL, American Academy of Orthopedic Surgeons, 1995, pp. 123-132.

16. Gelberman RH, Hergenroeder PT, Hargens AR, et al: The carpal tunnel syndrome: A study of carpal canal pressures. J Bone Joint Surg 63A:380-383, 1981

17. Szabo RM, Madison M: Carpal tunnel syndrome as a work-related disorder. In Repetitive Motion Disorders of the Upper Extremity. Rosemont, IL, American Academy of Orthopedic Surgeons, 1995, pp. 421-433.

18. Armstrong TJ: Cumulative trauma disorders of the upper limb and identification of work-related factors. In Occupational Disorders of the Upper Extremity. New York, Churchill Livingstone, 1992, p. 37.

19. Marras WS: Toward an understanding of dynamic variables in ergonomics. In Occupational Medicine: Ergonomics. Philadelphia, Hanley \& Belfus, 1992.

20. Sakai N: Hand pain related to keyboard techniques in pianists. Med Probl Perform Artists 7:63-65, 1992. 
21. Hochberg F, Leffert RD, Heller MD, Merriman L: Hand difficulties among musicians. JAMA 249:279-282, 1983.

22. Viikari-Juntura $E$ : The role of physical stressors in the development of hand/wrist and elbow disorders. In Repetitive Motion Disorders of the Upper Extremity. Rosemont, IL, American Academy of Orthopedic Surgeons, 1995, pp. 7-29.

23. Silverstein BA, Fine LJ, Armstrong TJ: Hand wrist cumulative trauma disorders in industry. Br J lnd Med 43:779-784, 1986.

24. Punnett L: Work-related musculoskeletal disorders in computer keyboard operation. In Repetitive Motion Disorders of the Upper Extrem- ity. Rosemont, IL, American Academy of Orthopedic Surgeons, 1995, pp. 43-48.

25. Meinke WB: The work of piano virtuosity: An ergonomic analysis. Med Probl Perform Art 10:48-61, 1995.

26. Hillberry BM: Dynamic effects of work on musculoskeletal loading. In Repetitive Motion Disorders of the Upper Extremity. Rosemont, IL, American Academy of Orthopedic Surgeons, 1995, pp. 107-108.

27. Hall SJ: Basic Biomechanics. St. Louis, Mosby-Year Book, 1991.

28. Higgins JR: Human Movement: An Integrated Approach. St. Louis, Mosby-Year Book, 1977.

\section{ANNOUNCEMENT}

The 8th European Congress on Performing Arts Medicine and Physiology of Music Making will take place in Mainz, Germany, October 14-15, 2000. English is the official congress language for all participants. The main topic will be "The Musician's Hand," including different aspects of hand and trauma surgery, neurology, orthopedics, rheumatology, dermatology, physiology, instrumental technique and methodology, ergonomics, physiotherapy, and other disciplines.

The congress will provide an opportunity through lectures, discussions, and workshops for an interdisciplinary exchange of experiences in prevention, diagnostic techniques, and treatment options of the medical problems connected with music making. The invitation to attend the congress is extended not only to physicians and physical therapists, but also to musicians of all kinds and styles, instrumental pedagogues, teachers of body techniques, and manufacturers of musical instruments.

The musician's hand deserves and needs an interdisciplinary meeting of this kind, since it is the most sensitive interface between instrumentalists and their instruments, with a highly specialized anatomical architecture and complicated function potential to enable the most impressive skilled movements of which man is capable. Only with the varied perspectives of different professional specialists joined together in an openminded environment will we learn more about the fascinating field of making music, as well as about the origin, diagnostic requisites, prevention, and therapies of music-induced pathologies.

The following is the rough outline for the program of this meeting.

- Welcome and introduction.

- The musician's hand and its meaning for the musician him. self or herself-seen by musicians. Statements for: piano and organ; stringed instruments; brass and woodwind. The role of instrumental methodology for the hand as taught in conservatories and music schools.

- Anatomy, physiology, and biomechanics of the musician's hand. Selected chapters for practical relevance by several authors.

- Clinical aspects 1: The musician's hand: rheumatology and dermatology: hypermobility syndrome; rheumatologic hand problems; hand surgery for arthritic conditions in musicians' hands; metabolic influence of medically prescribed drugs for the musician's hand; dermatologic hand problems in musicians.

- Clinical aspects 2: The musician's hand: hand surgery, traumatology, orthopedics: hand surgical examination of musicians; indications, planning, and techniques in hand surgery for musicians; nerve compression syndromes, neurology, surgery, especially CTS, endoscopic vs. open techniques; hand trauma in musicians: therapy, reimplantation, rehabilitation, prostheses, overuse, misuse; contractures in the musician's hand.

- Clinical aspects 3: The musician's hand: neurology: focal dystonias (several authors from neurology and hand surgery).

- Clinical aspects 4: The musician's hand: rehabilitation, physical therapy, body techniques: hand therapy.

- Free papers.

- Workshops (Alexander, Feldenkrais, etc.).
Where is Mainz? Mainz is an old German university town with Roman history, situated on the Rhine river, and close to Frankfurt. From the Frankfurt Airport (Europe's largest airport with convenient direct flights to most large American cities) to Mainz is only a 35-minute ride by public transportation.

What else can be done in the area in addition to attending the meeting? The Times nominated Johannes Gutenberg, the inventor of book printing with mobile letters, as "the man of the millennium." Gutenberg was born in Mainz in 1400 and spent most of his professional life there. Therefore, in 2000 the city of Mainz is celebrating Gutenberg's 600 th birthday with a number of special events.

Furthermore, the dates of the congress typically correspond to a lovely autumn, which is similar to the American "Indian summer." The vineyards surrounding Mainz in the hilly Rhine landscape are beautiful during October, with the grapes being harvested and offering a chance to taste the new wines, or at least some of the delicious older local white wines.

It is also possible to combine the meeting with a boat ride on the Rhine from Mainz on to Cologne and Bonn, providing the most beautiful of scenery.

How can you register for the congress? Send a bank draft of US\$110 (after August 1st: US\$135) to the DGfMM account number 643432609 at the Postbank Frankfurt-Germany bank, sorting number 50010060 , indicating your name, city, and "Congress 2000."

Please also write or fax the Congress Secretary to register, indicating your name, title, address, phone, fax, and e-mail. Further information will then be sent to you. The address for this is:

Frau T. Wentscher-Helpenstein

Secretary of the Deutsche Gesellschaft für Musikphysiologie und Musikermedizin

Katzenberg 123

D-55126 Mainz

Tel: $++49-6131-479565$

Fax: $++49-6131-479568$

e-mail: dgfmm@t-online.de

Internet: http://home.pages.de/ dgfmm

The scientific chair of the meeting, Prof. Dr. Jochen Blum, can also be reached through the secretary.

How can you get hotel information? Please contact the local tourist agency as soon as possible:

$$
\begin{gathered}
\text { Touristik Centrale Mainz } \\
\text { Verkehrsverein Mainz } \\
\text { Im Brücketurm am Rathaus } \\
\text { D-55116 Mainz } \\
\text { Tel: }{ }^{++49-6131-286210} \\
\text { Fax: }{ }^{++49-6131-2862155}
\end{gathered}
$$

Special rates for the congress are available at: Dorint Hotels Mainz: ++49-6131-9540; Hilton City Hotel Mainz: ++496131-2780. 